\title{
Relato de experiência: projeto Planeta Azul numa escola municipal de Lavras - MG
}

\author{
Experience report: Planeta Azul project in a municipal school in Lavras - MG
}

Antônio Gilmar Carvalho Tavares ${ }^{1}$, Sabrina Soares da Silva²

1 Mestre. Universidade Federal de Lavras (UFLA), Brasil. E-mail: toninhoql@yahoo.com.br

2 Professora. Universidade Federal de Lavras (UFLA), Brasil. E-mail: sabrinasilva@ufla.br

Recebido em: 29/05/2020 | Aprovado em: 20/10/2020

DOI: $10.12957 /$ interag. 2020.51362

\begin{abstract}
Resumo
As questões socioambientais estão cada vez mais em pauta nos ambientes escolares. Portanto, este trabalho busca relatar uma experiência em educação ambiental, ao ar livre, com crianças, realizada no Parque Ecológico Quedas do Rio Bonito (PEQRB), envolvendo o Projeto Planeta Azul e uma escola municipal no município de Lavras - Minas Gerais. Ressaltam-se a abrangência do termo Educação Ambiental (EA) e a importância de se trabalhar esse tema com atividades pedagógicas interdisciplinares e ações concretas. As atividades aconteceram em dois momentos distintos: sendo o primeiro dia na escola e o segundo no Parque Ecológico Quedas do Rio Bonito. $\mathrm{O}$ objetivo desse relato é descrever a experiência vivenciada nos dias de atividade que abordaram Educação Ambiental ao ar livre, por intermédio do projeto Planeta Azul. Participaram das atividades 120 estudantes com a idade entre oito e nove anos, alunos do terceiro ano do ensino fundamental. Tive a oportunidade de participar do projeto como extensionista, no dia de visita ao parque, proporcionando aos alunos atividades em meio à natureza, contribuindo para a experimentação prática e formação cidadã das crianças. Além disso, a experiência permitiu conhecer como a EA está sendo trabalhada dentro e fora da instituição escolar.
\end{abstract}

Palavras-chave: Educação Ambiental; Atividades ao Ar Livre; Relato de Experiência.

\begin{abstract}
Social and environmental issues are increasingly under consideration in school environments. This paper aims to report an experience with children in an outdoor environmental education held at the Ecological Park Quedas do Rio Bonito (PEQRB). The experience involved the Planeta Azul Project and a municipal school in the municipality of Lavras, state of Minas Gerais, Brazil. We highlight the scope of the term Environmental Education (EE) and the importance of working this theme with interdisciplinary pedagogical activities and concrete actions. The events took place at two different times: the first being at school and the second at the Ecological Park Quedas do Rio Bonito. This report describes the experience lived during the activity addressing Environmental Education outdoors through the Planeta Azul project. The activities involved 120 students of the third year of an elementary school aged between eight and nine years. I had the opportunity to participate in the project as an extensionist during the visit to the park, providing the student with activities in nature, contributing to the practical experimentation and civic education of children. Furthermore, the experience allowed me to understand how Environmental Education is worked inside and outside the school environment.
\end{abstract}

Área temática: Educação.

Linha de extensão: Meio-ambiente. 


\section{Introdução}

A discussão sobre a Educação Ambiental (EA) vinculada ao processo educativo teve início, formalmente, na década de $1960^{1}$, mas ideias que fomentam a preservação podem ser encontradas desde o século XVII².

Com uma nova abordagem metodológica e alternativas curriculares, a EA foi inserida nos Parâmetros Curriculares Nacionais (PCN's). Esses parâmetros fomentam a importância de se trabalhar a EA, no contexto formal e informal, em todos os níveis de escolaridade, como forma de transformação dos indivíduos no que tange a seus comportamentos, valores sociais, conhecimentos, habilidades, atitudes e competências, voltadas à conservação do meio ambiente, bem de uso comum do povo, essencial à sadia qualidade de vida e sua sustentabilidade ${ }^{3}$. Acredita-se, dentro dessa perspectiva, que é possível adequar o comportamento dos seres humanos ao meio ambiente de forma mais sustentável, pois existem muitos problemas que resultam na degradação ambiental.

A ambição de se gerar capital está degradando os recursos naturais de forma muito intensa, sem precedentes na nossa história ${ }^{4,5}$. O impacto que os seres humanos provocam no meio ambiente é crescente e irreversível. Configura-se, assim, a 'crise ecológica' que, somada à 'crise de valores', compõem o cenário em que a educação passa a ter grande relevância ${ }^{6}$. Portanto, abordar a EA no processo educativo possui um valor significativo, uma vez que são nos anos iniciais do educando que este forma a sua personalidade. Desenvolver atividades que ampliem seu contato com a natureza é oferecer às crianças oportunidades para que elas se sintam parte integrante do meio ambiente, desenvolvendo-se suas características psíquicas e emocionais ${ }^{7,8,9}$. As crianças estão em fase de desenvolvimento cognitivo, comportamental e perceptivo. Estão mais receptivas à apropriação de valores e comportamentos, enquanto os adultos já possuem hábitos arraigados e rotina estabelecida, o que reflete em sua resistência aos novos paradigmas pró-ambientais ${ }^{7,9,10}$.

Segundo Rosa e Carvalinho ${ }^{11}$, acreditar que os conteúdos ambientais transmitidos de forma direta são capazes de desenvolver uma consciência ecológica é um engano. Estes mesmos autores, reforçando que para aprender é preciso oportunidades, vivências e 
experiências, citou Ferreira (1998), Light (2006), Stewart e Craing (2000) e Lee (2011) como apoiadores da experimentação prática ${ }^{11}$. Corroborando com a ideia de que é preciso ter experiências, Vigotsky salienta que o processo de reconstrução interna de um indivíduo ocorre por meio da interação com uma ação externa em que os envolvidos se constituem como atores pela internalização dos significados que são desenvolvidos, construídos e reelaborados no desenvolvimento de suas interações sociais ${ }^{12}$.

Nesse contexto, o objetivo deste relato é descrever a experiência vivenciada pelo autor nos dias de atividades que abordaram EA, no âmbito do projeto Planeta Azul, em uma escola municipal de Lavras, MG, e na incursão realizada no Parque Ecológico Quedas do Rio Bonito, no mesmo município.

\section{Contextualização}

O Projeto planeta Azul foi criado em 2011, quando alguns alunos e professores da Universidade Federal de Lavras (UFLA) perceberam a demanda que as crianças apresentaram referentes aos assuntos relacionados à conservação e preservação da natureza, bem como o uso e degradação dos recursos naturais. Identificando essa lacuna e a necessidade de abordar, cada vez mais, a EA nas escolas, esse grupo elaborou o projeto Planeta Azul. Porém, a consolidação da proposta ocorreu apenas em 2012. Desde então, mais de 1.000 crianças já participaram do projeto.

O público participante das atividades de EA, em uma das escolas nas quais o projeto atuava em 2018, foi um total de 120 crianças, com idade entre oito e nove anos, do terceiro ano do Ensino Fundamental, residentes no município de Lavras, MG. O Projeto Planeta Azul tinha suas atividades realizadas às terças feiras, das $13 \mathrm{~h}$ às $15 \mathrm{~h}$, com duas turmas, e às quartas feiras, das $7 \mathrm{~h}$ às $8 \mathrm{~h}$ e das $9 \mathrm{~h}$ às $10 \mathrm{~h}$, também com duas turmas. Cada turma tinha uma hora de atividades, no projeto, semanalmente.

\section{Descrição}

A etapa do projeto aqui relatada, no primeiro dia, iniciou-se com uma das turmas, na biblioteca da escola, com uma tempestade de ideias sobre o tema poluição sonora e do 
solo. A extensionista do projeto perguntou para os alunos o que eles sabiam ou já tinham ouvido falar sobre o assunto em pauta. Os alunos começaram a falar tudo o que eles sabiam e já tinham ouvido falar, principalmente relatos de algo que aconteceu ou acontecia em suas casas.

Em seguida, foram projetados alguns slides que envolviam os tipos de poluição e a extensionista foi explicando os malefícios que poderiam causar. Logo após essa etapa, realizou-se um novo debate com os alunos, para averiguar o que eles entenderam sobre a exposição. Os alunos comentavam o que acontecia em suas famílias ou com vizinhos, ou seja, relacionaram o tema com seu cotidiano, fazendo o elo entre o que foi apresentado e sua vivência individual. Para complementar, a extensionista passou um desenho animado sobre a importância do solo para a vida do ser humano, relacionando o consumo dos nutrientes pelos alimentos com os nutrientes do solo.

Após o desenho, a extensionista realizou novo debate, para analisar o que foi assimilado. Eles disseram que os vegetais extraem os nutrientes do solo e, consequentemente, quando os seres humanos os consomem, estão absorvendo esses nutrientes. Também, disseram que não podemos jogar lixo em qualquer lugar, porque contamina o solo. A apreensão do conteúdo discutido foi considerada adequada, pois os alunos conseguiam relatar e interpretar o que foi apresentado. Eles complementaram as explicações com exemplos sobre comportamentos pró-ambientais, relacionados ao tema proposto.

Ao final das atividades, a extensionista entregou uma atividade impressa para os alunos fazerem em casa, buscando reforçar os conteúdos sobre poluição apresentados. A tarefa era relacionar a coluna da esquerda (fotos/charges) com a coluna da direita (tipos de poluição). A análise da assimilação do conteúdo seria feita averiguando os acertos que os alunos tiveram.

No segundo dia, a equipe do projeto Planeta Azul promoveu uma incursão ao Parque Ecológico Quedas do Rio Bonito, conhecido na região como Poço Bonito (PB). Participaram, na primeira visita ao parque, 33 alunos. Cada turma participou em um dia diferente, para que fosse possivel acompanhar, de forma próxima, as crianças. Ao chegar 
ao parque, conversei rapidamente com os alunos e dei início às atividades. Pedi a eles que formassem duas filas, e eles mesmos dividiram-se em dois grupos de alunos e alunas. Meu objetivo era que eles conhecessem a natureza fora dos livros e da escola e sua importância para a vida no planeta.

Fávero $^{13}$ ressalta que um dos propósitos da EA é o contato direto com o meio ambiente, diferente da educação formal, restrita aos ambientes institucionais. Por meio das atividades de EA, o aprendizado é construído em consequência da interação dos envolvidos com o ambiente em que estão ocorrendo as experiências. Os resultados não são expressos por documentos, como na educação formal, mas, sim, pela análise dos pensamentos e comportamentos. Os processos de ensino e aprendizagem são construídos participativamente, e não são unidirecionais, como a educação formal, se enquadrando na educação não formal. $O$ conhecimento construído participativamente é capaz de promover a ação e reflexão sobre o mundo para transformá-lo ${ }^{14}$.

Como tudo era novidade, eles falavam muito alto. Logo aproveitei para falar da poluição sonora, integrando com a atividade ministrada na biblioteca da escola há alguns dias atrás. A apreensão do conteúdo pelas crianças foi avaliada por meio das respostas dadas quando o extensionista questionou sobre a poluição sonora. Comparamos com as respostas do dia anterior, quando foram questionados sobre a poluição sonora na escola, antes da apresentação do conteúdo. A ideia era salientar a complexa relação entre o ser humano e seu comportamento na natureza, pois relacionar-se com outras espécies é um componente do processo educativo ambiental. Depois dessa atividade inicial, fizemos uma caminhada até o início da Trilha do Sauá, que um caminho em condições e distância interessantes adequados para a faixa etária e experiência das crianças.

No início da trilha, há uma fonte de água natural. As crianças beberam água e puderam também encher suas garrafas. Aproveitei para integrar o conteúdo do projeto ministrado na escola sobre poluição da água. Fiz uma pergunta após a ingestão de água: "O que vocês sentiram ao beber água natural?" As repostas mais dadas foram: agradável, gelada, boa, gostosa, normal. Neste momento, conversamos com os alunos que a natureza está em constante transformação e é afetada pelos comportamentos e ações das pessoas. 
Conversamos sobre a necessidade de agirmos de forma respeitosa com o ambiente, para que seja mantida a qualidade da água e continuarmos a ter o privilégio de beber água potável direto da fonte.

Ao adentrar a trilha, percebi que os alunos estavam motivados e desenvoltos para fazer perguntas. Dessa forma, houve uma participação maior dos alunos, favorecendo a construção do conhecimento e debates sobre as dúvidas que ali iam surgindo. Expliquei que as matas são o hábitat de insetos que serviam de alimento para os peixes e que não deveríamos desmatar, para preservar todas essas espécies. Pude salientar a importância da preservação e conservação dos elementos da natureza, relacionando com atividade anterior do projeto, na escola, quando foi discutido sobre a cadeia alimentar. Em uma das paradas, comentei sobre a pureza do ar. Um aluno comentou: "as árvores fazem oxigênio". Junto com outros extensionistas, respondíamos às perguntas que iam surgindo.

EA apenas no ambiente escolar não basta. É preciso vivências e experiências diretas no ambiente natural, ou seja, in loco, capazes de estimular emoções e sensações que contribuem para o comportamento adequado junto à natureza. ${ }^{15,11}$ Dessa forma, a proposta do contado direto com a natureza, fazendo uma trilha em meio à mata e bebendo água direto da fonte, permite criar uma identificação com ambiente, para desenvolver um sentimento de pertencimento, e também estimular vínculos emocionais. Guimarães $^{16}$ chama a atenção de que o ser humano perdeu a noção de ser parte integrante do meio ambiente, tornando-se individualista. Para transformar a realidade, é preciso resgatar essa noção. Muitas crianças, nascendo em meio urbano, não possuem contato com a natureza, fazendo-as acreditar que podem dominar e controlar tudo ${ }^{17}$.

Ao final do passeio, uma roda de conversa com o grupo propiciou a análise dos resultados da intervenção. Neste momento, o debate final possibilitou comparar a visão inicial e final das crianças sobre as questões discutidas. Logo após esse momento, retornamos para fazer um lanche, enquanto aguardávamos o transporte para retornar à cidade. 


\section{Considerações finais}

Em minha participação no projeto e, em particular, nessas atividades relatadas, acredito que esse projeto ofereceu conteúdos teóricos, práticos e vivenciais para a formação da cidadania comprometida em respeitar o meio ambiente. Além disso, foram desenvolvidas atividades durante a visita ao parque ecológico, o que foi muito interessante para a formação das crianças e dos próprios extensionistas. Constatei que gerir uma turma de 33 alunos do ensino fundamental exigiu-me um conhecimento a fundo nos temas abordados.

O conteúdo abordado no dia da visita ao parque foi planejado de acordo com as atividades anteriores ministradas na escola, a fim de promover uma reflexão entre a relação entre os seres humanos e a natureza. Durante as atividades no parque, os alunos foram incentivados a ter contato com os elementos da natureza, tais como: terra, água, a flora local, entre outros. Eles puderem conhecer in loco estes elementos, e não apenas por meio dos conteúdos transmitidos na escola e pelo projeto. A todo o momento na visita ao parque, procurei manter um diálogo com os alunos, incentivando-os a vivenciarem a natureza, deixando-os à vontade para fazerem perguntas e questionamentos.

Quanto maior o tempo que uma criança passa na natureza, mais comportamentos pró-ambientais ela poderá desenvolver durante sua infância ${ }^{18}$ e na idade adulta ${ }^{19}$. São experiências que permitem um melhor entendimento do próprio meio ambiente e de suas inter-relações ${ }^{20,21}$. "Não aprendemos amar a Terra lendo livros sobre isso, nem em livros de ecologia integral. A experiência própria é o que conta” (22, p. 86).

Participar do Projeto Planeta Azul foi uma oportunidade muito valiosa para meu aprendizado. Atividades como essas são passos importantes para a construção de um novo saber e entendimento da importância da natureza para a vida do planeta. Para atender às expectativas dos educandos, é necessário integrar os conteúdos escolares e o mundo real, para formar cidadãos reflexivos, criativos, capazes de se comprometerem com a conservação e preservação da natureza, e usufruí-la de forma sustentável. 


\section{Contribuição dos autores}

Antônio Gilmar Carvalho Tavares - autor responsável

Sabrina Soares da Silva: orientadora

\section{Referências}

1. RODRIGUES, L. H.; DARIDO, S. C. Educação Física escolar e meio ambiente: reflexões e aplicações pedagógicas. Efdeportes, Bueno Aires. n. 100, 2006. Disponível em: < https://www.efdeportes.com/efd100/ma.htm>. Acesso em: 20 de maio de 2020.

2. ROCHA, R.G.; Ecoideologias associadas aos movimentos ambientais: contribuições para o campo da educação ambiental. Educar em revista, Curitiba, n 27, p. 55-73, 2006.

3. Brasil. Lei 9.795, de 27.04.1999. Dispõe sobre Educação Ambiental e institui a Política Nacional de Educação Ambiental, e dá outras providências. DOU 28.04.1999.

4. PITANO, S. C.; NOAL, R. E. Horizontes de diálogo em educação ambiental: contribuições de Milton Santos, Jean-Jacques Rousseau e Paulo Freire. Educação em Revista, Belo Horizonte, v.25, n.03, p.283-298, dez. 2009. 5. JACOBI, Pedro; Educação ambiental, cidadania e sustentabilidade. Cadernos de Pesquisa, n. 118, p. 189-205, março/ 2003.

6. CHASSOT, A. Alfabetização Científica: questões e desafios para a educação. 5 ed. Ijuí/RS. Editora Unijuí, 2010. 368p.

7. BISSOLI, M. F. Desenvolvimento da personalidade da criança: o papel da educação infantil, Psicologia em Estudo, Maringá, v. 19, n. 4 p. 587-597, out./dez. 2014.

8. CARVAlHO, R. N. S. A construção do currículo dá e na creche: um olhar sobre o cotidiano. Dissertação de Mestrado, Faculdade de Educação, Universidade Federal do Amazonas, Manaus, AM. 2011. 169p.

9. MEDEIROS, A. B.; MEDONÇA, M. J. S. L.; SOUSA, G. L.; OlIVEIRA, I. P. A importância da educação ambiental na escola nas séries iniciais. Revista Faculdade Montes Belos, v. 4, n.1, set.2011.

10. CARli, A. A.; MARTINS, S. B. Educação Ambiental: premissa inafastável ao desenvolvimento econômico e sustentável. Rio de Janeiro: Lumen Juris, 2014.448 p. 
11. ROSA, P. F.; CARVALHINHO, L. A. D. A educação ambiental e o desporto na natureza: uma reflexão crítica sobre os novos paradigmas da educação ambiental e o potencial do desporto como metodologia de ensino. Movimento, Porto Alegre, v. 18, n. 03, p. 259-280, jul/set de 2012.

12. VIGOTSKY, L. S. A formação social da mente: o desenvolvimento dos processos psicológicos superiores. 7 ed. São Paulo, SP. M. Fontes, 2007. 182p.

13. FÁVERO, O. Educação não formal: contextos, percursos e sujeitos. Educação \& Sociedade, Campinas, v. 28, n. 99, p. 614-617, maio/ago. 2007.

14. FREIRE, P. Conscientização: teoria e prática da libertação. Uma introdução ao pensamento de Paulo Freire. São Paulo: Moraes, 1980. 102p.

15. MARINHO, A.; INÁCIO, H. L. D. Educação Física, meio ambiente e aventura: um percurso por vias instigantes. Revista Brasileira de Ciências do Esporte, Curitiba, v. 28, n. 3, p. 55-70, maio 2007.

16. GUIMARÃES, M. A dimensão ambiental na educação. 10. ed. Campinas: Papirus, 2010. $96 \mathrm{p}$.

17. KONDRACT, H.; MACIEL, M. D. Educação ambiental para a escola básica: contribuições para o desenvolvimento da cidadania e da sustentabilidade. Revista Brasileira de Educação, São Paulo, v. 18, n. 55, p. 825-846, out./dez. 2013.

18. CHENG, J. C.; MONROE, C. M. Children's affective attitude toward nature. Environment and Behavior, Beverly Hills, v. 44, n. 1, p. 31-49, 2012.

19. HINDS, J.; SPARKS, P. Engaging with the natural environment: the role ofaffective connection and identity. Journal of Environmental Psychology, London, v. 28, n. 2, p. 109-120, June 2008.

20. CARVALHO, J.; BOÇÓN, R. Planejamento do traçado de uma trilha interpretativa através da caracterização florística. Revista Floresta, Curitiba, v. 34, n. 1, p. 23-32, jan./abr. 2004.

21. MENDONÇA, R. Educação ambiental vivencial. In: FERRARO-JUNIOR, L. A. Encontros e caminhos: formação de educadoras(es) ambientais e coletivos educadores. Brasília: MMA, 2007. v. 2, p. 117-130.

22. GADOTTI, M. Pedagogia da terra. 5. ed. São Paulo: Fundação Peirópolis, 2000. 217 p. 